\title{
Experimental Study on the Influence of Spur Dikes Spacing on Local Scouring
}

\author{
Jian NING ${ }^{1, a}$, Guo-Dong $\mathrm{LI}^{2, \mathrm{~b},{ }^{*}}$ and Shan-Shan $\mathrm{LI}^{3, \mathrm{c}}$ \\ ${ }^{1,2,3}$ State Key Laboratory Base of Eco-hydraulic in Arid Area, Xi'an University of Technology, China. \\ aemail: yongjie123kaka@126.com, bemail: gdli2008@xaut.edu.cn, \\ cemail: 1104293823@qq.com.
}

Keywords: spur dikes spacing; scour depth; local scour; cover effect.

\begin{abstract}
Spur dikes spacing is an important consideration for spur dike of channel layout. It is of important engineering significance to reasonably determine the spacing of the spur dikes. It is found that the maximum scour depth of each spur dike is at the spur dike head. The scour depth of the first dam is the largest, and the scour depth increases with the increase of intensity of water flow. When the river width narrowing rate is 0.25 , the spur dike layout should be considered from the perspective of the cover effect of the first spur dike, and the spacing of the spur dikes is between $2 \mathrm{l}$ and 3l. The experiment results can effectively reflect the influence of different spur dikes spacing on the scouring patterns and the scour depth of the dam head.
\end{abstract}

\section{Introduction}

Spur dikes spacing is the key to the treatment engineering benefit and engineering investment. Therefore, in order to achieve the best effect with the minimum amount of spur dike, the spacing of spur dike must be determined reasonably. Spur dike spacing is one of the important parameters. Nakagawa [1] and Fukuoka et al. [2] according to the empirical method, a certain multiple of the dam length is used to determine the distance between the spur dikes. They every man according to his experience, may give different spur dike spacing. Chang Futian and Feng Wei [3] use "cusp method", according to the law of the variation of flow velocity in the main channel along the river, put forward the principle of seeking the optimal spacing, and the relation formula of spacing for groin system is obtained. Experimental results show that keeps the main channel water flowing uniformly within the range of ding dam group is necessary. Reasonable dam spacing should be followed: the first and second spacing is about (8-9)l, the second and third spacing is about (1-1.5)l, the rest spacing is roughly equal, generally about 2l. Kong Xiangbai et al. [4] calculate the spacing of dam from the perspective of local energy loss caused by groin. From the results, the above methods have been the spur dike spacing is bigger than spur dike spacing in practical engineering. The main reason is that under the condition of different cross section shape and different water, consider only spur dike length factors spacing is too simple. It but also ignores local scour of head of groin in actual engineering.

Hao Zhang et al. [5] analyze the scour problem of spur dike group. The study shows that the maximum scour depth dikes along the head of groin is reduced, and the fourth spur dike scour depth can be ignored in a group of 9 spur dikes and the spur dike spacing for 3l. H. Karami et al. [6] find the maximum scour depth is located at the first spur dike. In view of the stability of spur dikes, a protection spur dike is set before the first one in order to reduce the impact of scour on the safety of spur dike. Through the flume test, it is found that the distance between the cover spur dike and the first one is 1.5-2 times of the groin length. Tominaga and Sadat [7] found the scour depth and scour volume decreases with the increase of spur dike spacing when the spur dike spacing less than $4 \mathrm{l}$ for impervious spur dike. When spur dike spacing is 4 l, the maximum scour depth decreases to $44 \%$ of the single spur dike scour maximum scour depth. When the spur dike distance is $6 \mathrm{l}$, the maximum scour depth and erosion volume were larger than the spur dike spacing for 41 . Considering the perspective of the maximum scour depth and erosion volume, $4 \mathrm{l}$ is the most suitable for spur dike spacing. Manish Pandey et al. [8] summarized the problems generated in the process of the layout 
of the spur dike group, and considered the spacing between the spur dike group from the perspective of the flow field structure of the spur dike group and the maximum scouring depth of the groin heads of each spur dike group.

In this paper, through the study of the layout of the spur dike group and the interaction between the flow field and the riverbed, the shielding effect between the spur dikes between the spur dike group is fully considered, and the response law of the water flow intensity and the spacing of the spur dike group to the local deformation of the riverbed is obtained.

\section{Experiments}

The flume channel is $10 \mathrm{~m}$ long, $0.4 \mathrm{~m}$ wide, $0.5 \mathrm{~m}$ deep, consists of entrance section, transition section, and viewing section and recycle zone (Fig.1). The transition section is composed of gravel and coarse sediment, mainly to prevent water occurs when it enters the observation period of sediment rolled up, make the water can flow smoothly. Spur dike layout in the water tank on the right side, the first spur dike section starting at point $1 \mathrm{~m}$ distance observation, four equally spaced along to decorate, spur dike for impervious material, $10 \mathrm{~cm}$ long, $1 \mathrm{~cm}$ wide, $50 \mathrm{~cm}$ high, spur dike in the submerged condition. Selection of sediment grain size $\mathrm{D}_{50}=0.473 \mathrm{~mm}$, sediment grading curve as shown in figure 2. The experiment conditions and results of spur dikes head scouring are shown in table 1 , where the negative value represents scouring and the positive value represents silting.

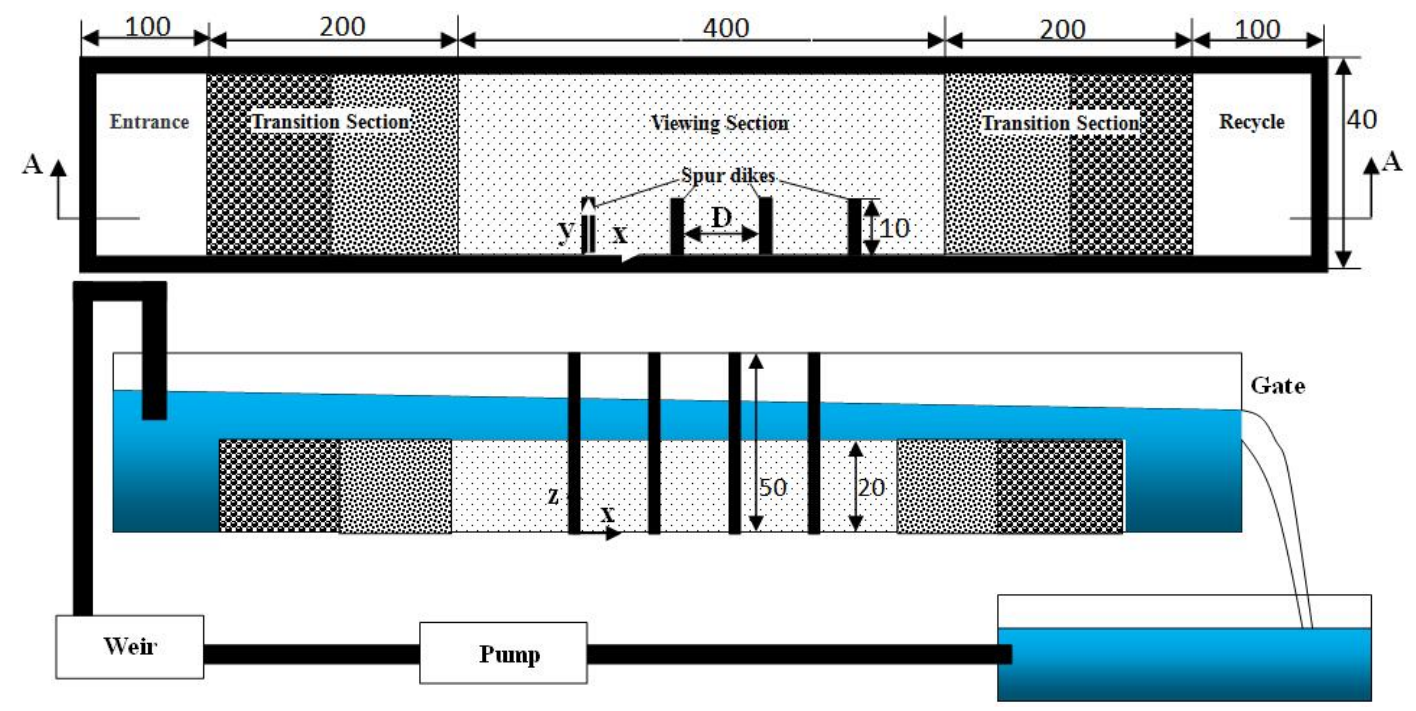

Fig. 1 Experiment setting (top: plan view, bottom: A-A sectional view, Unit: cm)

Table 1 Experiment conditions and results

\begin{tabular}{|c|c|c|c|c|c|c|c|}
\hline \multirow{2}{*}{ Case } & \multirow{2}{*}{ Spacing } & \multirow{2}{*}{$\begin{array}{c}\text { Flow rate } \\
{\left[\mathrm{cm}^{3} / \mathrm{s}\right]}\end{array}$} & \multirow{2}{*}{$\begin{array}{c}\text { Depth of } \\
\text { water } \\
\text { [cm] }\end{array}$} & \multicolumn{4}{|c|}{ Scouring Depth $[\mathrm{cm}]$} \\
\hline & & & & $\mathrm{I}$ & II & III & IV \\
\hline 1 & \multirow{3}{*}{21} & 9620 & 8.9 & -11.45 & -6.25 & -4.7 & -4.25 \\
\hline 2 & & 7346.8 & 7.66 & -8.76 & -4.53 & -3.91 & -2.96 \\
\hline 3 & & 5061.3 & 6.8 & -8.3 & -2.3 & -1.8 & 0.6 \\
\hline 4 & \multirow{3}{*}{31} & 9620 & 8.71 & -13.16 & -7.16 & -4.76 & -4.09 \\
\hline 5 & & 7346.8 & 7.47 & -12.02 & -6.32 & -6.82 & -4.12 \\
\hline 6 & & 5061.3 & 8.1 & -6.6 & 0.14 & 0.25 & -2.67 \\
\hline 7 & \multirow{3}{*}{41} & 9620 & 10.44 & -11 & -3.83 & -8.35 & -5.83 \\
\hline 8 & & 7346.8 & 9.47 & -8.9 & -4.6 & -6.3 & -4.87 \\
\hline 9 & & 5061.3 & 8.16 & -6.89 & -6.68 & -5.64 & -3.84 \\
\hline
\end{tabular}




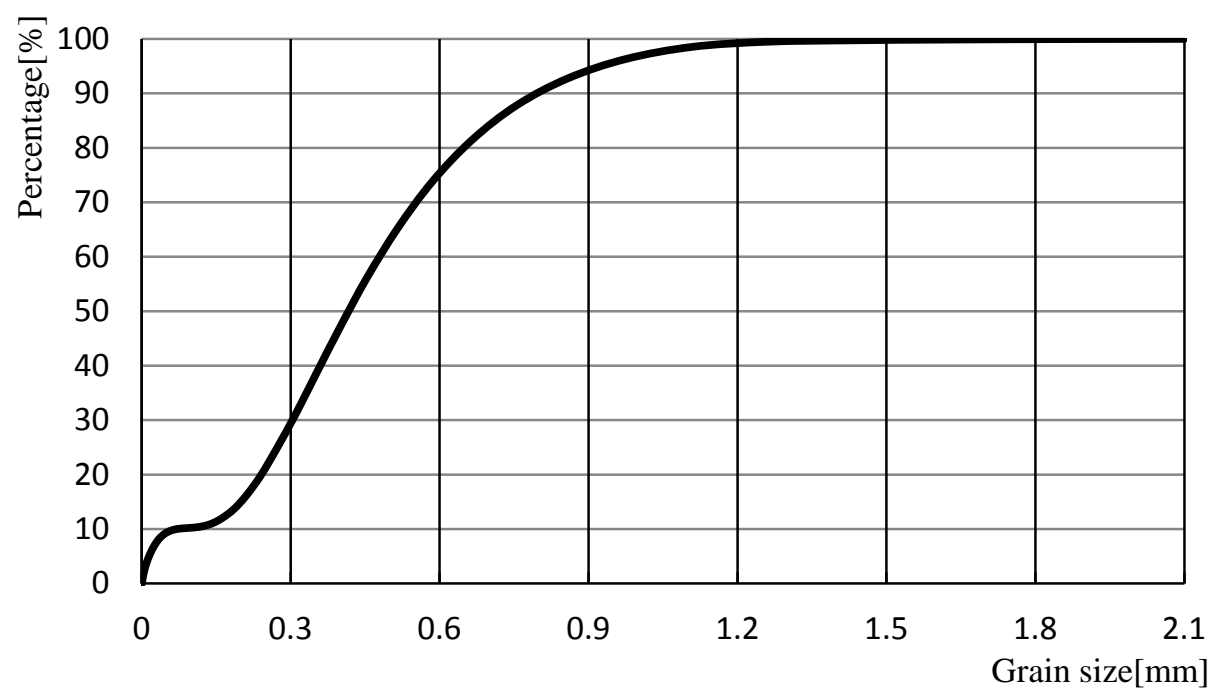

Fig. 2 Sediment grading curve

\section{Results}

The depth of local scour hole is related to the strength of water flow and the spur dikes spacing. The spacing is small, and the covering effect of the first groin is large. On the contrary, the spacing is large, and the covering effect of the first groin is small. The paper analyzes the influence of different influencing factors on the local scouring of the dam group, and obtains the variation rule of the scour depth of the dam head under three different dam spacing conditions with different inlet flow.

Fig.3 shows the influence curve of different flow rate on scour depth with spur dikes spacing 21 . Fig.4 shows the scour patterns of different flow rate with spur dikes spacing 2l, (case 3). At the same spur dike, the scouring depth increases with the increase of the flow. In the same flow situation the erosion depth of dam head decreases successively, and the scour depth of dam I head is the maximum. This is because of the same type of layout and small spacing of all spur dikes. The covering effect of the dam I play a protective role on dam II, III and IV head scour. Due to the influence of local scour patterns of dam I, the scour hole of dam II, III and IV cannot be fully developed, resulting in an integral scour zone in the mainstream area. As flow decreases, and the flow intensity is abate. When the flow rate is $5061.3 \mathrm{~cm}^{3} / \mathrm{s}$, the cover effect of spur dike I can only affect the spur dike II, III. The spur dike IV head silting more obvious than scour. This is the main reason that the height of the bed is $0.6 \mathrm{~cm}$ higher than that of the original bed. Therefore, when the spacing of the dam group is $2 \mathrm{l}$, it is believed that the covering effect of the first dam can basically affect dam II, III and IV.

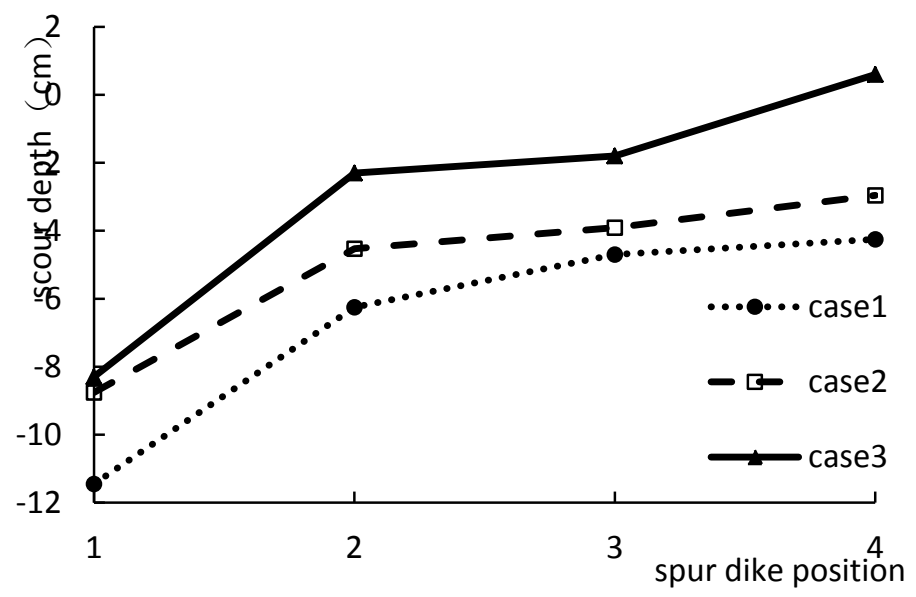

Fig. 3 The influence curve of different flow rate on scour depth with spur dikes spacing 21 


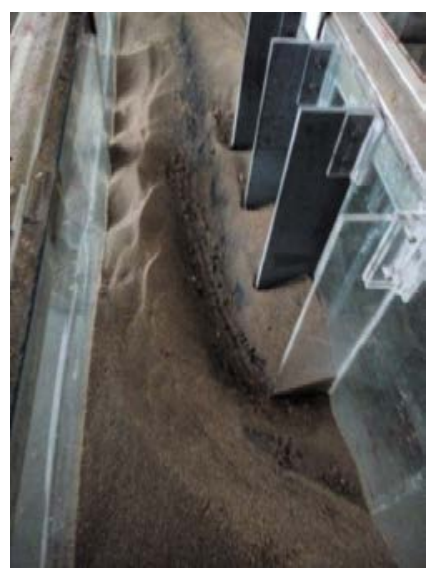

Fig. 4 The scour patterns of different flow rate with spur dikes spacing $2 \mathrm{l}$

Fig.5 shows the influence curve of different flow rate on scour depth with spur dikes spacing 31. Fig. 6 shows the scour patterns of different flow rate with spur dikes spacing 31 (case 6). The scour depth of dam I head is the maximum, the scour depth of dam I and II increases with the flow, and the dam III and IV scour depth change rule is different. When the flow is small, the shielding effect of the first dam can partially affect dam II. Because spur dike II, III not only affected by the spur dike I cover effect, also affected by drowning effect. Meanwhile the spur dike IV cannot be affected. At the spacing 31 the current flow cannot wash sediment downstream, only silting up between the spur dikes II, III. When the flow rate is $5061.3 \mathrm{~cm}^{3} / \mathrm{s}$, the sediment silted up between the spur dikes I,II. Therefore, when the spacing of the dam group is 3l, when the flow rate is large, the covering effect of the first spur dike can affect dam II and III. When the flow rate is small, the covering effect of the first spur dike can partially affect the spur dike II.

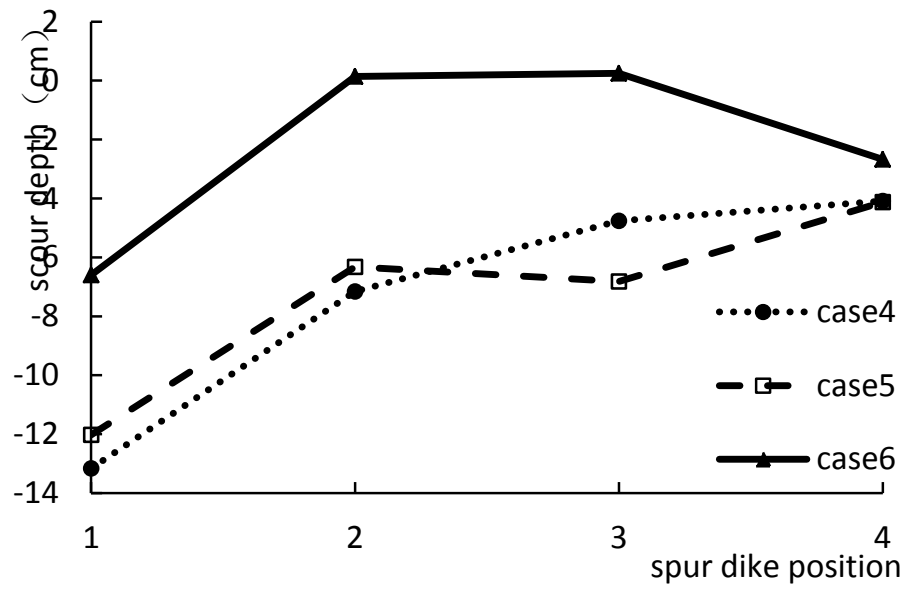

Fig. 5 The influence curve of different flow rate on scour depth with spur dikes spacing 31

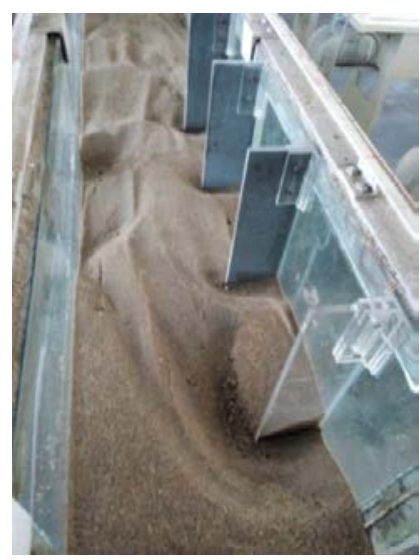

Fig. 6 The scour patterns of different flow rate with spur dikes spacing 31 
Fig.7 shows the influence curve of different flow rate on scour depth with spur dikes spacing 4 l. Fig.8 shows the scour patterns of different flow rate with spur dikes spacing 41 (case 9). In the same place, the spur dike I, III, IV head scour depth change rule along the same. The scour depth increases with the flow rate, but the spur dike II head scour depth change rule is different. The spur dike I covering effect is weak at the spacing 4l. The spur dike III and IV basic is not affected basically. It can be clearly seen that each local scour hole is relatively complete, forming four separate scour holes. When the flow rate is $5061.3 \mathrm{~cm}^{3} / \mathrm{s}$, the effective length of spur dike II, III and IV on the local scour gets smaller. The results in the phenomenon that scour depth of spur dike head in turn reduces. Therefore, when the spacing of the dam group is 4l, when the flow rate is large, the covering effect of the first spur dike can affect partly dam II. When the flow rate is small, the covering effect of the first spur dike cannot affect the spur dike II, III, IV.

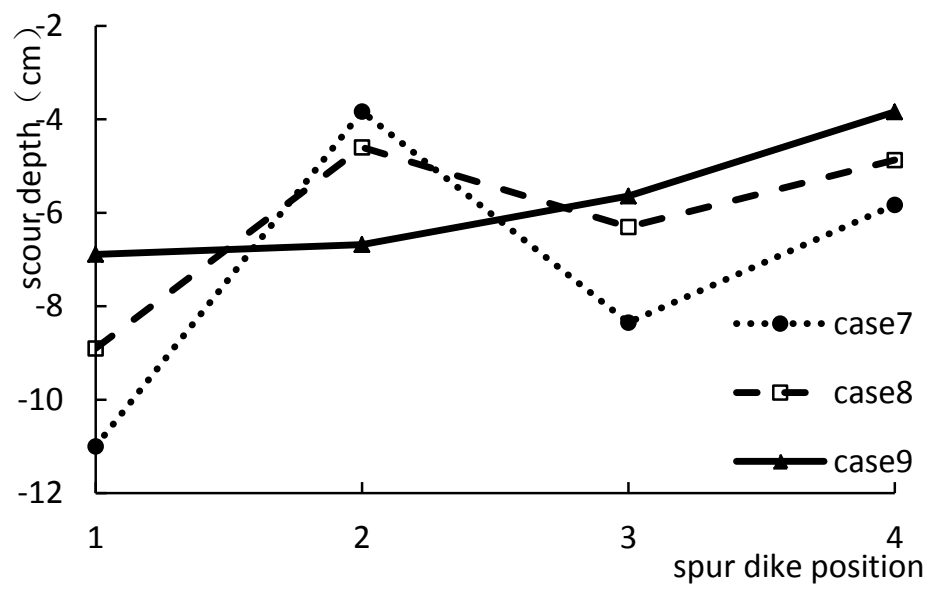

Fig. 7 The influence curve of different flow rate on scour depth with spur dikes spacing 41

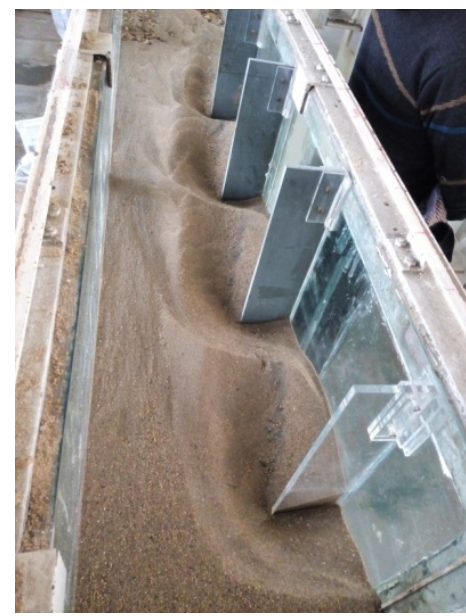

Fig. 8 The scour patterns of different flow rate with spur dikes spacing $4 \mathrm{l}$

\section{Conclusion}

The influence of different inflow strength and spacing of the dam group on river bed morphology is studied in the paper. It is found that the maximum scour depth of each spur dike is at the top of the dam. The scour depth of the first dam is the largest, and the scour depth increases with the increase of intensity of water flow. The change law varies according to the influence of the flow intensity and the cover effect of the first spur dike. When the spacing of the dike group is 2l, the cover effect of the first spur dike can affect the scour depth of the head of the dam II, III and IV. When the spacing is 3l, the cover effect of the first spur dike can affect the scour depth of the head of the dam II and III. When the spacing is 4l, the cover effect of the first spur dike can only affect the scour depth of the head of the dam II. Therefore, when the river width narrowing rate is 0.25 , the spur dike layout should be considered from the perspective of the cover effect of the first spur dike, and 
the spacing of the spur dikes is between $2 \mathrm{l}$ and $3 \mathrm{l}$. The study on the spacing of the ding dam group is a flume test result. The specific engineering application also needs to be combined with the actual engineering detailed analysis.

\section{References}

[1] Nakagawa. K., Kawahara. Y., and Tamai, N. Experimental study on hydraulic characteristics of flows in embayments[J]. Annu. J. Hyd. Eng., 1995, 9,595-600.

[2] Fukuoka. S., Nakagawa, Sumi. T., etc. Advances in river sediment research [J], Taylor \& Francis Group, London, 2013.

[3] Chang Futian, Feng Wei. Experiment at Investigation of Reasonable Spacing among Spur Dikes[J]. Journal of Hohai University (Natural Sciences), 1992(4):7-14.

[4] Kong Xiangbai, Cheng Niansheng. Studies on local head losses of spur and submerged dikes [J]. Journal of Nanjing Hydraulic Research Institute. 1992,(4):387-395.

[5] Hao ZHANG, Hajime NAKAGAWA, etc. Prediction of 3D Flow Field and Local Scouring Around Spur Dikes[J]. Annual Journal of Hydraulic Engineering. 2005, 49:1003-1008.

[6] H. Karami., A. Ardeshir., K. Saneie. etc. Reduction of local scouring with protective spur dike[G]. World Environmental and Water Resources Congress 2008.

[7] Tominaga. A., Sadat. S.H. Combination of permeable and impermeable spur dikes to reduce local scour and to create diverse river bed [G]. River Sedimentation: Proceedings of the 13th International Symposium on River Sedimentation, Germany, September, CRC Press, 101. 2016: 19-22.

[8] Manish Pandey, Z. Ahmad, P. K. Sharma. Scour around impermeable spur dikes: a review [J]. ISH Journal of Hydraulic Engineering. 2017:12-13. 